\title{
Prognostic Value of Craniovertebral Junction Diffusion Tensor Imaging in Patients with Chiari Type 1 Malformation
}

\author{
Haydar GOK ${ }^{1}$, Sait NADERI ${ }^{2}$ \\ ${ }^{1}$ University of Health Sciences, Okmeydani Teaching and Research Hospital, Department of Neurosurgery, Istanbul, Turkey \\ ${ }^{2}$ University of Health Sciences, Umraniye Teaching and Research Hospital, Department of Neurosurgery, Istanbul, Turkey
}

Corresponding author: Haydar GOK haydarctf@hotmail.com

\section{ABSTRACT}

AIM: To examine the spinal cord status by using diffusion tensor imagıng (DTI) and tractography preoperatively and postoperatively in patients with Chiari malformation type 1 (CM1) and compare the results with the data obtained from healthy people.

MATERIAL and METHODS: Overall, 48 patients (33 patients with CM1, and 15 in the control group for DTI and tractography measurements) were included in the study. Mean age was $37.7 \pm 11.8$ years (minimum and maximum: 12 and 57 years). The DTI and tractography data were obtained from the craniocervical region in patients with $\mathrm{CM} 1$ and control group. Patients with $\mathrm{CM} 1$ were operated using the suboccipital decompression technique without opening the dura. Surgical results were evaluated using Chicago Chiari Outcome Scale (CCOS) and Asgari scale.

RESULTS: Based on the CCOS and Asgari scale results, the surgical technique was determined to be clinically beneficial. The DTI and tractography values from the pontobulbar, cervicomedullary, and spinal cord C3-4 levels in patients with CM1 were compared to those of the control group. These values were observed to be near normal after surgery in patients with CM1.

CONCLUSION: Based on the improvement in DTI-tractography data observed in our study, DTI and tractography can serve as a guiding measurement method for assessing the prognosis of patients with CM1.

KEYWORDS: Chiari type 1 malformation, Diffusion tensor imaging, Tractography, Chicago chiari outcome scale, Asgari scale

\section{INTRODUCTION}

$\mathrm{C}$ hiari malformation is defined as the varying degrees of displacement of the posterior fossa structures through

the foramen magnum into the cervical spinal canal. Chiari malformation type 1 (CM1) is considered to occur because of the small and shallow posterior cranial fossa. Smaller posterior fossa volume is generally the result of insufficient development of the occipital bone $(24,26,29,37)$. The treatment options of CM1 vary based on the patient's symptoms, imaging, and neuropsychological tests. Several methods have been described as the optimal surgical treatment, some of which are controversial. Because of the lack of a standard outcome measure, there is no widely accepted tool to compare the results of each surgical method, which is a major limitation in Chiari research.
Diffusion tensor imagıng (DTI) and tractography have been used in several areas, especially those involving congenital anomalies. One of the most common purposes of using DTI and tractography is to evaluate the infiltration, destruction, or displacement of the white matter tracts. DTI indexes are affected by microstructural alterations that affect the diffusion of water molecules, and this forms the basis for using DTI indexes to identify spinal cord pathology. In the present study, we aimed to investigate the pre- and postoperative structural changes in white matter tracts in patients with $\mathrm{CM} 1$ by using DTI and tractography.

\section{MATERIAL and METHODS}

Overall, 48 patients (34 females, 14 males) were included in the study. The mean age was 37.7 years ( \pm 11.8 years), with 
the youngest being 12 years old and the oldest 57 . Cases were categorized into the following three groups:

Group-A: The control group, which revealed no pathology on the craniocervical MRI (Table I). The average tonsillar herniation in this group was $-2.78 \mathrm{~mm}( \pm 2.19 \mathrm{~mm}$; the lowest being $-7 \mathrm{~mm}$, and the highest $2 \mathrm{~mm}$ ).

Group-B: Patients with CM1 without syringomyelia (Table I). The average tonsillar herniation was $12 \mathrm{~mm}( \pm 2 \mathrm{~mm}$; the lowest being $10 \mathrm{~mm}$, and the highest $15 \mathrm{~mm}$ ).

Group-C: Patients with CM1 with syringomyelia (Table I). The average tonsillar herniation was $11 \mathrm{~mm}( \pm 2 \mathrm{~mm}$; the lowest being $7 \mathrm{~mm}$, and the highest $13 \mathrm{~mm}$ ).

Craniospinal MRI and CT scans were obtained in all patients to evaluate the craniocervical junction (Figure 1).

DTI and tractography were performed in all patients with CM1 (Figure 2). Preoperative and early postoperative period apparent diffusion coefficient (ADC) and fractional anisotropy (FA) values at the pontobulbar region, cervicomedullary junction, and the C3-4 spinal cord level were calculated. ADC and FA diffusion maps were created in the axial plane and then reformatted as cervical tractography and diffusion maps on the sagittal plane to examine the craniocervical region by using DTI and tractography. For simplicity, pontobulbar level was named as ' $a$ '; cervicomedullary junction as ' $\boldsymbol{b}$ '; and the C3-4 spinal cord level as the ' $c$ ' region.
A suboccipital craniectomy followed by $\mathrm{C} 1$ laminectomy was performed in all the patients with CM1.

DTI and tractography values were calculated at the end of the first postoperative month using the same method, and the clinical outcome was evaluated using Chicago Chiari Outcome Scale (CCOS) (Table II) and Asgari scale (Table III) at the end of the sixth postoperative month in all patients.

Statistical analysis was performed using the SPSS 17.0 statistical package software. Continuous variables were summarized as medians or means and SDs. The influence of all the categorical variables was tested using the chi-square test. A two-sided $\mathrm{P}$ value of $<0.05$ was considered to be statistically significant. A multivariate analysis was then carried out using a forward stepwise logistic regression analysis.

\section{RESULTS}

Besides tonsillar herniation, syringomyelia was observed in 16 patients, focal myelomalacia in 2, platybasia in 1, and the fourth ventricle expansion in 1.

\section{Clinical Results}

The average duration of symptoms was 3.7 years among all patients. Suboccipital headache when coughing, neck pain, and arm pain with numbness were the most frequent complaints (Table IV).

Table I: The Number of Cases and the Mean Ages of Each Group

\begin{tabular}{ccc}
\hline Group Name & Number of Cases & Mean Age of the Group (Years) \\
\hline A & $15(9$ women, 6 men) & $37.8 \pm 11.6$ (min-max: 21-56) \\
\hline B & $17(14$ women, 3 men) & $39.7 \pm 10.7$ (min-max: 17-57) \\
\hline C & $16(11$ women, 5 men) & $35.3 \pm 11.6$ (min-max: 12-55) \\
\hline
\end{tabular}

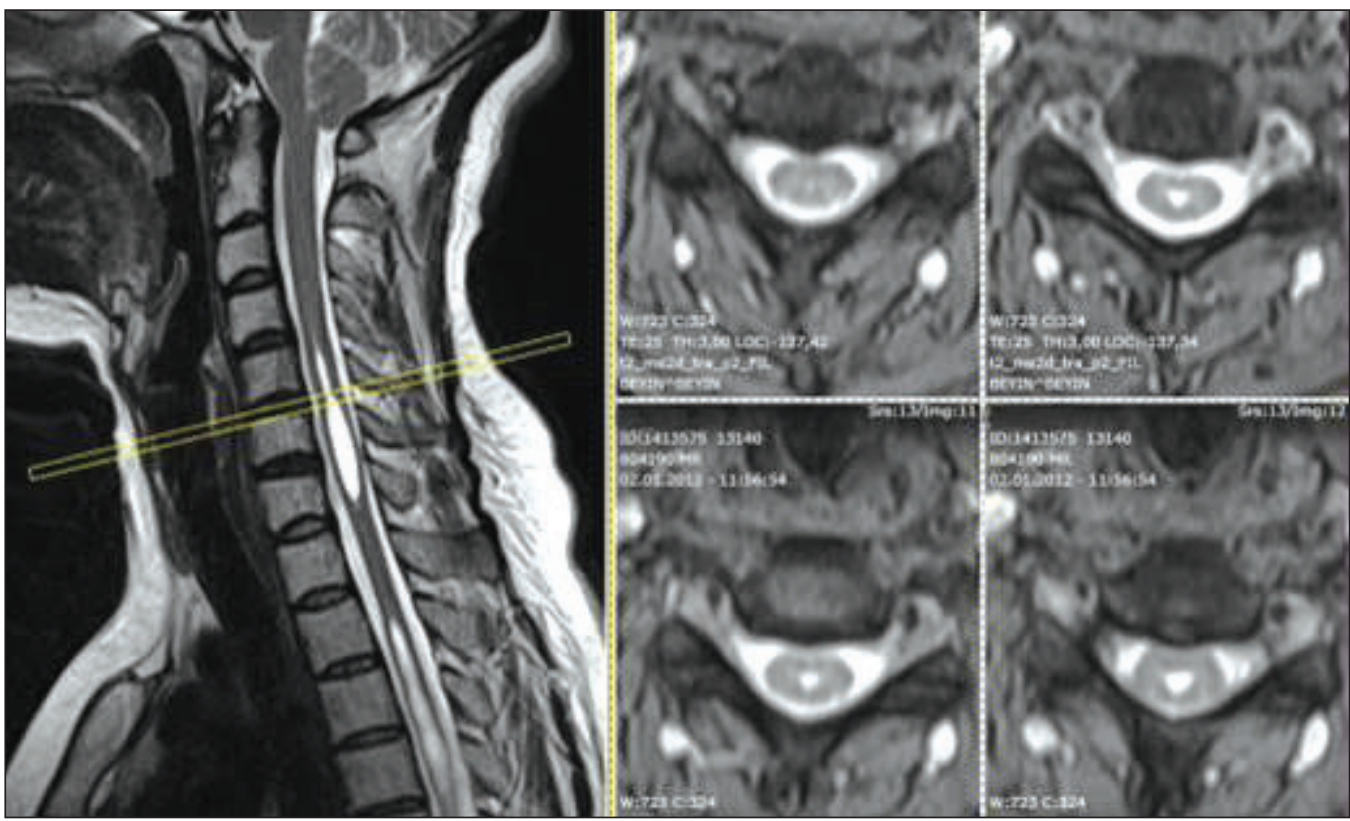

Figure 1: Preoperative MR imaging of patient with syringomyelia-related CM1. 

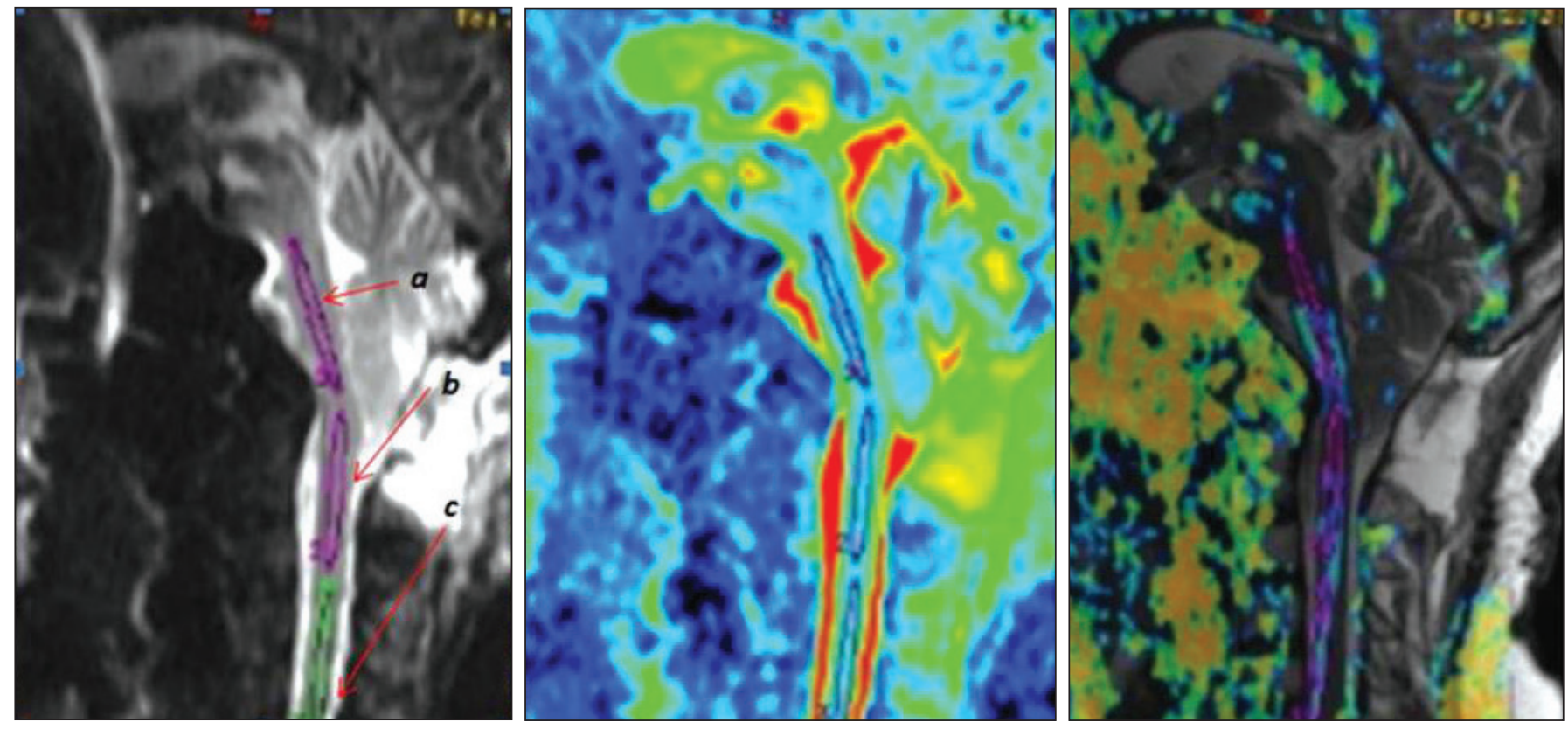

Figure 2: DTI and tractography imaging of a patient with CM1.

Table II: Chicago Chiari Outcome Scale (CCOS)

\begin{tabular}{|c|c|c|c|c|}
\hline Pain & Non-pain & Functionality & Complications & Total Score \\
\hline $\begin{array}{l}\text { 2: Unchanged/refractory } \\
\text { to meds/onset of new } \\
\text { managed symptoms }\end{array}$ & $\begin{array}{l}\text { 2: Unchanged/refractory } \\
\text { to meds/onset of new } \\
\text { managed symptoms }\end{array}$ & $\begin{array}{l}\text { 2: Moderate } \\
\text { impairment }(<50 \% \\
\text { attendance) }\end{array}$ & $\begin{array}{l}\text { 2: Persistent } \\
\text { complication-well } \\
\text { controlled }\end{array}$ & 8: Impaired outcome \\
\hline $\begin{array}{l}\text { 4: Resolved/no onset of } \\
\text { new symptoms }\end{array}$ & $\begin{array}{l}\text { 4: Resolved/no onset of } \\
\text { new symptoms }\end{array}$ & 4: Fully functional & $\begin{array}{l}\text { 4: Uncomplicated } \\
\text { course }\end{array}$ & 16: Excellent outcome \\
\hline
\end{tabular}

Table III: Asgari Scale (Clinical Evaluation Scoring)

\begin{tabular}{ll}
\hline Observation & Score \\
\hline Cranial Nerve Involvement & 2 \\
\hline Signs of spinal disease, but no difficulty with arms or walking & 1 \\
\hline Slight difficulty using arms/hands or walking; can work full-time & 2 \\
\hline Moderate disability with arms/hands & 2 \\
\hline Complete disability with arms/hands & 3 \\
\hline Difficulty walking; prevents full-time employment & 3 \\
\hline Need assistance to walk & 4 \\
\hline Chairbound or bedridden & 5 \\
\hline
\end{tabular}


Table IV: Preoperative Symptoms and Signs of All CM1 Patients

\begin{tabular}{|c|c|c|c|}
\hline Symptoms & n (\%) & Signs & n (\%) \\
\hline Headache & $30(90)$ & Dysesthesia & $10(30)$ \\
\hline Neck pain & $30(90)$ & Loss of sensation & $9(27)$ \\
\hline Arm pain & $27(82)$ & Cerebellar signs & $8(24)$ \\
\hline Heat loss of sensation & $10(30)$ & Hyperactive reflexes of the upper extremity & $8(24)$ \\
\hline Numbness in the extremities & $9(27)$ & Hyperactive reflexes in lower limb & $7(21)$ \\
\hline Diplopia & $9(27)$ & Lower cranial nerve involvement & $2(6)$ \\
\hline Leg pain & $4(12)$ & Babinski signs & $2(6)$ \\
\hline Tinnitus & $4(12)$ & Loss of strength in the lower extremities & $2(6)$ \\
\hline Limb weakness & $3(9)$ & Nystagmus & $1(3)$ \\
\hline Dysphasia & $1(3)$ & Loss of strength in the upper extremities & $1(3)$ \\
\hline
\end{tabular}

Marked neck pain was observed in the early postoperative period that gradually decreased over time, especially toward the sixth postoperative month. Patients who complained of only pain and numbness preoperatively showed excellent improvement. Partial improvement was observed regarding dysesthetic complaints, especially of hands and arms, as well as other non-localizing symptoms, such as dizziness, visual symptoms, sleep problems, coughing fits.

The pain was completely resolved in 24 patients, whereas it was mild to moderate enough to be tolerated using simple analgesics in 9 patients. Furthermore, in 17 patients, symptoms unrelated to pain were completely resolved. On the other hand, neuropathic symptoms in 11 patients, and other symptoms unrelated to pain in 5 patients partly persisted. In 2 patients, the moderate activity limitation observed during the preoperative period decreased after surgery. No surgical complications were observed in any patient. According to CCOS, 30 patients scored 13 or higher, whereas 3 scored 9-12. Notably, none of the patients scored 8 or less.

According to the Asgari scale, the symptoms were slight in 15 patients, moderate in 15 patients, and severe in 3 patients preoperatively. At the sixth postoperative month, 14 patients had no symptoms, 15 had slight symptoms, 3 had moderate symptoms, and 1 patient had severe symptoms. Upon evaluation of patients' symptom severity based on the Asgari scale, a difference of 2 or more points was observed between the scores of the preoperative and sixth postoperative month in 27 patients. Notably, this points difference was less than 2 in six patients. Consequently, based on this scale, clinical improvement was observed in 27 patients.

\section{Radiological Results}

Postoperative MRI scans revealed normalization of the subarachnoid spaces, which appeared to be tight preoperatively, especially at the cervicomedullary region. Patients with syringomyelia demonstrated clinical improvement. Although no radiological improvement was observed in the size of the syrinx cavities during the early postoperative period, a partial regression was reported in the sixth postoperative month (Figure 3).

During the preoperative assessment, no differences were observed between Group-A and Group-B regarding ADC values obtained from the "a" and "b" regions, but a statistically significant differences were observed in values obtained from the " $c$ " region $(\mathrm{p}<0.05)$. In addition, no differences were observed between Group-A and Group-B regarding the FA values obtained from the " $\mathrm{C}$ " region, but statistically significant differences were observed in values obtained from the "a" and "b" regions $(p<0.05)$ (Table V).

Furthermore, no differences were observed between Group-A and Group-C regarding ADC values obtained from the "a" and "c" regions, but values obtained from "b" region exhibited a statistically significant difference $(p<0.05)$. Similarly, no differences were observed between Group-A and Group-C regarding FA values obtained from the "a" and "c" regions $(p>0.05)$, but values obtained from the "b" region showed a statistically significant difference $(p<0.05)$ (Table V).

During the postoperative assessment, no differences were noted between Group-A and Group-B regarding ADC values obtained from the "a" region, but statistically significant differences were observed for values obtained from the "b" and " $c$ " regions $(p<0.05)$. Moreover, no differences were observed between Group-A and Group-B regarding FA values obtained from the "a" and "c" regions, but a statistically significant difference was noted for values obtained from the "b" region $(p<0.05)$ (Table V).

No differences were noted between Group-A and Group-C regarding ADC values obtained from the "a" and " $c$ " regions, whereas a statistically significant difference was observed in values obtained from the " $b$ " region $(p<0.05)$. In addition, no differences were observed between Group-A and Group-C regarding FA values obtained from the "a" and "c" regions, but a statistically significant difference was noted for values obtained from the "b" region $(\mathrm{p}<0.05)$ (Table V). 


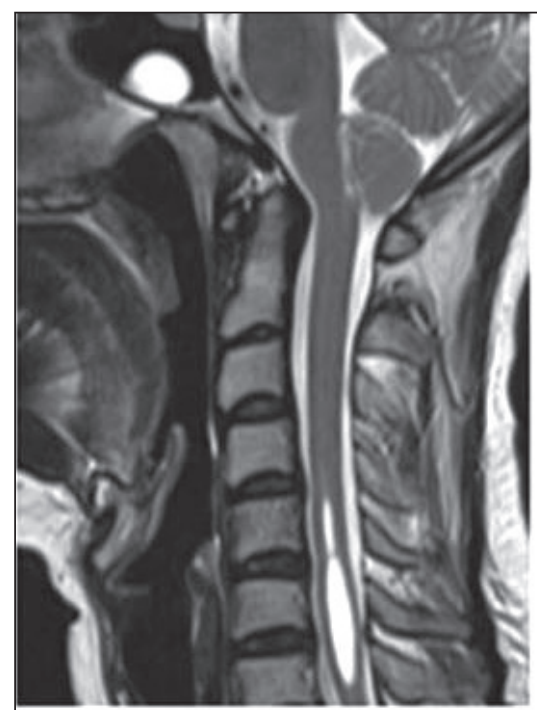

Preoperative

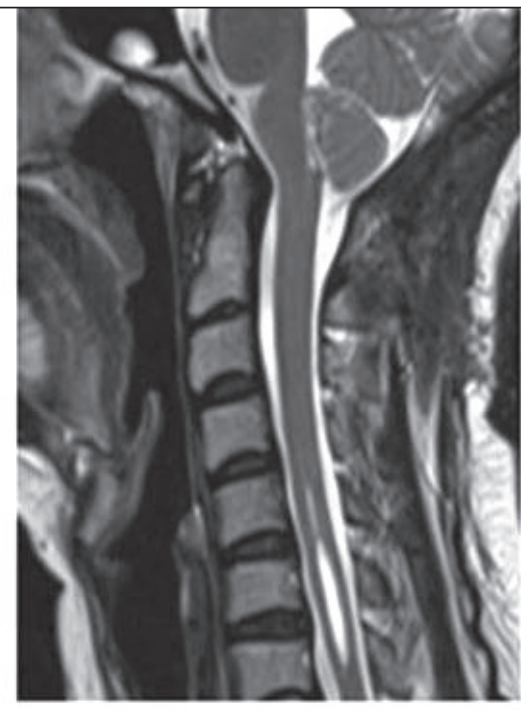

Postoperative $1^{\text {st }}$ month

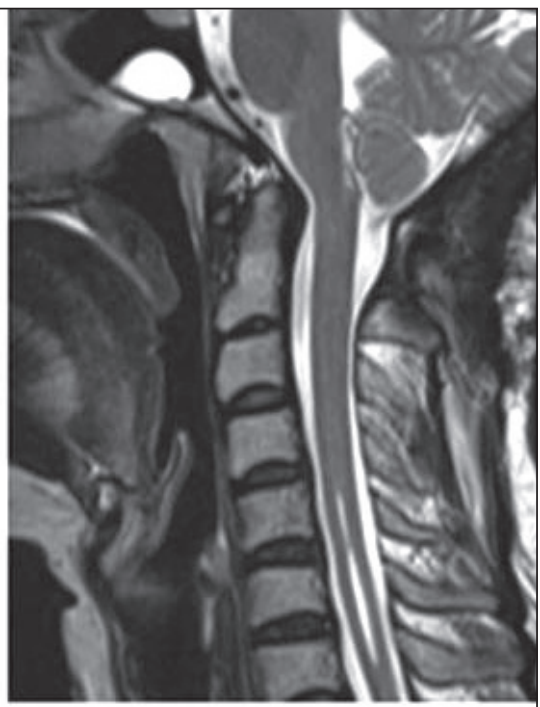

Postoperative $6^{\text {th }}$ month

Figure 3: Partial regression of syrinx cavity observed at the end of the sixth month.

Table V: Mean DTI and Tractography Values of Groups

\begin{tabular}{lcccccc}
\hline & \multicolumn{1}{c}{ FA } & & ADC \\
\hline Group-A & $\mathbf{a}$ & $\mathbf{b}$ & $\mathbf{c}$ & $\mathbf{a}$ & $\mathbf{b}$ & $\mathbf{c}$ \\
\hline Group-B Preoperative & $0.475 \pm 0.05$ & $0.474 \pm 0.04$ & $0.506 \pm 0.06$ & $0.793 \pm 0.07$ & $0.920 \pm 0.28$ & $0.897 \pm 0.21$ \\
\hline Group-B Postoperative & $0.438 \pm 0.05$ & $0.429 \pm 0.05$ & $0.511 \pm 0.06$ & $0.795 \pm 0.07$ & $0.936 \pm 0.12$ & $0.930 \pm 0.12$ \\
\hline Group-C Preoperative & $0.454 \pm 0.09$ & $0.497 \pm 0.06$ & $0.476 \pm 0.13$ & $0.780 \pm 0.06$ & $0.876 \pm 0.09$ & $1.108 \pm 0.79$ \\
\hline Group-C Postoperative & $0.413 \pm 0.07$ & $0.466 \pm 0.09$ & $0.497 \pm 0.16$ & $0.814 \pm 0.08$ & $0.879 \pm 0.16$ & $0.999 \pm 0.79$ \\
\hline
\end{tabular}

FA: Fractional anisotropy; ADC: Apparent diffusion coefficient.

For Group-B, no differences were observed upon the comparison of pre- and postoperative ADC values of any region. No differences were observed regarding pre- and postoperative FA values obtained from the "c" region $(p>0.05)$, but statistically significant differences were detected for values from the "a" and "b" regions (Table V). For Group-C, no differences were observed upon the comparison of pre- and postoperative ADC or FA values from any region (Table V).

\section{- DISCUSSION}

DTI and tractography studies have been conducted mostly for traumatic spinal cord injury, cervical spondylotic myelopathy (CSM), spinal cord tumors, multiple sclerosis, syringomyelia, transverse myelitis, and CM2, rather than CM1. Currently, this method is commonly used to evaluate the infiltration, destruction, or displacement of the white matter tracts by using fiber tractography $(4,5,7,13,25,27,35,36)$. In acute human spinal cord injury (SCl), DTI shows a reduction in diffusivity, particularly $F A$ and $A D C$, around the injury site $(7,27)$. Contrarily, in chronic $\mathrm{SCl}$, the injury site is characterized by increased diffusivity. In addition, FA values and connection rates of fiber tracking have been shown to correlate with the motor score in patients with chronic cervical cord injury (5). In patients with CSM, DTI indexes appear to depend on the degree of cord damage. Symptomatic patients have lower FA values and higher ADC measures at the compressed level compared with asymptomatic patients with radiological features of cord compression (13). Measurement of diffusion indexes within the spinal cord tumors suggests that higher tumor mass is characterized by a decrease in FA and an increase in ADC (30).

Therefore, based on this imaging method, it may be possible to view the function of the spinal cord and the properties of signals in the descending and ascending tracts in patients with CM1.

Several surgical treatment methods have been recommended for $\mathrm{CM} 1$, some of which are considered to be controversial. Suboccipital craniectomy with concurrent $\mathrm{C} 1$ laminectomy is the widely accepted conventional surgical treatment. However, the literature reports no well-established methods that can 
fully assess the results of decompression, probably because of the limited knowledge regarding the pathophysiology of the disease. Moreover, retrospective studies have not provided enough data to set guidelines that can direct the treatment algorithm. The current data reveals that no link exists between the age and results, and that surgery offers excellent results in patients with mild or moderate neurological deficits. Notably, it was reported that preoperative pathology improves after surgery in more than $83 \%$ of patients. The symptoms that mostly show improvement are headache; neck pain; and those related to the cerebellum or brainstem compressions, such as dysphagia, ataxia, nystagmus, and diplopia. Notably, poor outcome is observed in patients with syrinx (33). Nonetheless, these evaluations are subjective, and objective data is required to determine the prognosis. Therefore, based on the imaging method (DTI and tractography), it may be possible to view the function of the spinal cord and the properties of signals in the descending and ascending tracts in patients with CM1.

Milhorat et al. reported that central cord lesions are caused by irreversible damage, and occurs mostly in patients with syringomyelia $(17,18)$. Nagib reported that the best improvement after surgery was observed in patients with scoliosis (with an angle of less than $30^{\circ}$ ), head and neck pain, and sleep apnea (20). Notably, motor and sensory deficits were characterized by the least recovery. In addition, patients with small posterior fossa volume exhibited better recovery than those with normal-sized posterior fossa in their study. On the other hand, even though the results vary depending on the surgical technique applied, symptoms related to syringomyelia, such as pain, scoliosis, and loss of sensation, tend to show less improvement. The lack of a standard outcome measure is one of the major limitations in Chiari research. It has limited the ability to compare the results of various studies. Recently, a group from the University of Chicago has proposed that the Chicago Chiari Outcome Scale (CCOS) is promising as a standard measure for patients with CM1. Moreover, they investigated whether there were any predisposing factors that influenced the postoperative surgical outcome (1).

In addition to the preoperative MRI, Asgari scoring enabled to evaluate the patients on a scale based clinical assessment (8). Points were assigned for various neurological impairments and totaled to classify the patient's symptoms as slight (clinical score 1-3), moderate (clinical score 4-6), or severe (clinical score 7-10). All patients underwent decompression surgery, namely suboccipital craniectomy, laminectomy, and duraplasty, and were evaluated using the MRI and the clinical scale postoperatively. The radiological outcome was rated as either sufficient or insufficient decompression, and the clinical improvement was defined as a change in the score by 2 or more points.

Per the CCOS and Asgari scale, the surgical technique that we performed on patients with $\mathrm{CM} 1$ was quite successful. The surgical technique that involved posterior fossa decompression without opening the dura mater led to remarkable clinical improvement in patients with CM1. DTI and tractography values of all patients with CM1 were compared with the normal group, and it was observed that FA values at the pontobulbar and C3-4 regions were near normal after surgery in patients with CM1 without syringomyelia. Moreover, FA values at the same locations were near normal in patients with $\mathrm{CM} 1$ with syringomyelia. This postoperative "normalization" corroborates the excellent clinical results gauged by CCOS and Asgari scale and suggests that DTI and tractography could be used as valuable tools to predict the prognosis of patients with CM1.

On the other hand, the postoperative FA values at the cervicomedullary region being closer to the isotropic value in all patients with CM1 (with or without syringomyelia) could be probably from the increase in free movement of water molecules in all directions (isotropic diffusion). In addition, it would have been because of the planar anisotropy of water molecules owing to the intersecting complex anatomical structures in this region of the spinal cord.

\section{CONCLUSION}

Nonetheless, our limited number of patients and short followup period may have prevented us from making a definitive conclusion that DTI and tractography might be an excellent prognostic tool in patients with CM1. Therefore, further randomized controlled trials involving large series of patients and long-term follow-up are needed to adequately determine the prognostic role of DTI and tractography in patients with CM1.

\section{口 REFERENCES}

1. Aliaga L, Hekman KE, Yassari R, Straus D, Luther G, Chen J, Sampat A, Frim D: A novel scoring system for assessing Chiari malformation Type I treatment outcomes. Neurosurgery 70: 656-664; discussion 664, 2012

2. Alperin N, Kulkarni K, Loth F, Roitberg B, Foroohar M, Mafee MF, Lichtor T: Analysis of magnetic resonance imaging-based blood and cerebrospinal fluid flow measurements in patients with Chiari I malformation: A system approach. Neurosurg Focus 11: E6, 2001

3. Ducreux D, Lepeintre JF, Fillard P, Loureiro C, Tadié M, Lasjaunias P: MR diffusion tensor imaging and fiber tracking in 5 spinal cord astrocytomas. AJNR Am J Neuroradiol 27:214216, 2006

4. Duhmke RM, Cornblath DD, Hollingshead JRF: Tramadol for neurophatic pain. Cochrane Database Syst Rev 2: CD003726, 2004. (Update in. Cochrane Database Syst Rev 3: CD003726, 2006)

5. Ellingson BM, Ulmer JL, Kurpad SN, Schmit BD: Diffusion tensor MR imaging in chronic spinal cord injury. AJNR Am J Neuroradiol 29:1976-1982, 2008

6. Ergun R, Akdemir G, Gezici AR, Tezel K, Beskonakli E, Ergungor F, Taskin Y: Surgical management of syringomyeliaChiari complex. Eur Spine J 9:553-557, 2000

7. Facon D, Ozanne A, Fillard P, Lepeintre JF, Tournoux-Facon C, Ducreux D: MR diffusion tensor imaging and fiber tracking in spinal cord compression. AJNR Am J Neuroradiol 26:15871594, 2005 
8. Fischer EG: Posterior fossa decompression for Chiari I deformity, including resection of the cerebellar tonsils. Childs Nerv Syst 11:625-629, 1995

9. Hasan KM, Alexander AL, Narayana PA: Does fractional anisotropy have better noise immunity characteristics than relative anisotropy in diffusion tensor MRI? An analytical approach. Magn Reson Med 51:413-417, 2004

10. Iskandar BJ, Hedlund GL, Grabb PA, Oakes WJ: The resolution of syringohydromyelia without hindbrain herniation after posterior fossa decompression. J Neurosurg 89:212216, 1998

11. Kanpolat Y, Unlu A, Savas A, Tan F: Chiari type I malformation presenting as a glossopharyngeal neuralgia: Case report. Neurosurgery 48:226-228, 2001

12. Karagoz F, Izgi N, Kapijcijoglu Sencer S: Morphometric measurements of the cranium in patients with Chiari type I malformation and comparison with the normal population. Acta Neurochir (Wien) 144:165-171; discussion 171, 2002

13. Kerkovský M, Bednarík J, Dušek L, Sprláková-Puková A, Urbánek I, Mechl M, Válek V, Kadanka Z: Magnetic resonance diffusion tensor imaging in patients with cervical spondylotic spinal cord compression: Correlations between clinical and electrophysiological findings. Spine (Phila Pa 1976) 37:48-56, 2012

14. McGirt MJ, Nimjee SM, Floyd J, Bulsara KR, George TM: Correlation of cerebrospinal fluid flow dynamics and headache in Chiari I malformation. Neurosurgery 56:716-721; discussion 716-721, 2005

15. Milhorat TH, Bolognese PA: Tailored operative technique for Chiari type I malformation using intraoperative color Doppler ultrasonography. Neurosurgery 53:899-905; discussion 905896, 2003

16. Milhorat TH, Bolognese PA, Nishikawa M, Francomano CA, McDonnell NB, Roonprapunt C, Kula RW: Association of Chiari malformation type I and tethered cord syndrome: Preliminary results of sectioning filum terminale. Surg Neurol 72: 20-35, 2009

17. Milhorat TH, Capocelli AL Jr, Anzil AP, Kotzen RM, Milhorat RH: Pathological basis of spinal cord cavitation in syringomyelia: Analysis of 105 autopsy cases. J Neurosurg 82:802-812, 1995

18. Milhorat TH, Chou MW, Trinidad EM, Kula RW, Mandell M, Wolpert C, Speer MC: Chiari I malformation redefined: Clinical and radiographic findings for 364 symptomatic patients. Neurosurgery 44:1005-1017, 1999

19. Milhorat TH, Nishikawa M, Kula RW, Dlugacz YD: Mechanisms of cerebellar tonsil herniation in patients with Chiari malformations as guide to clinical management. Acta Neurochir (Wien) 152:1117-1127, 2010

20. Nagib MG: An approach to symptomatic children (ages 4-14 years) with Chiari type I malformation. Pediatr Neurosurg 21: 31-35, 1994

21. Pillay PK, Awad IA, Little JR, Hahn JF: Symptomatic Chiari malformation in adults: A new classification based on magnetic resonance imaging with clinical and prognostic significance. Neurosurgery 28:639-645, 1991

22. Rhoton A: Management of syringomyelia. In: Kaye A, Black $P$, (eds). Operative Neurosurgery. London: Churchill Livingstone, 2000:1743-1754
23. Sakamoto H, Nishikawa M, Hakuba A, Yasui T, Kitano S, Nakanishi N, Inoue Y: Expansive suboccipital cranioplasty for the treatment of syringomyelia associated with Chiarimalformation. Acta Neurochir (Wien) 141:949-960; discussion 960-941, 1999

24. Sansur CA, Heiss JD, DeVroom HL, Eskioglu E, Ennis R, Oldfield EH: Pathophysiology of headache associated with cough in patients with Chiari I malformation. J Neurosurg 98:453-458, 2003

25. Schwartz ED, Hackney DB: Diffusion-weighted MRI and the evaluation of spinal cord axonal integrity following injury and treatment. Exp Neurol 184:570-589, 2003

26. Sgouros S, Kountouri M, Natarajan K: Posterior fossa volume in children with Chiari malformation type I. J Neurosurg 105:101-106, 2006

27. Shaw D: The fundamental principles of nuclear magnetic resonance. In: Wehrli FW, Shaw D, Kneeland JB (eds). Biomedical Magnetic Resonance Imaging. New York: VCH, 1988:1-46

28. Sindou M, Chávez-Machuca J, Hashish H: Cranio-cervical decompression for Chiari type I-malformation, adding extreme lateral foramen magnum opening and expansile duroplasty with arachnoid preservation. Technique and long-term functional results in 44 consecutive adult cases-comparison with literature data. Acta Neurochir (Wien) 144:1005-1019, 2002

29. Stovner LJ, Bergan U, Nilsen G, Sjaastad O: Posterior cranial fossa dimensions in the Chiari I malformation: Relation to pathogenesis and clinical presentation. Neuroradiology 35:113-118, 1993

30. Takayasu M, Takagi T, Hara M, Anzai M: A simple technique for expansive suboccipital cranioplasty following foramen magnum decompression for the treatment of syringomyelia associated with Chiari I malformation. Neurosurg Rev 27:173177, 2004

31. Taylor WD, Hsu E, Krishnan KRR, MacFall JR: Diffusion tensor imaging: Background, potential, and utility in psychiatric research. Biol Psychiatry 55:201-207, 2004

32. Tubbs RS, Elton S, Grabb P, Dockery SE, Bartolucci AA, Oakes WJ: Analysis of the posterior fossa in children with the Chiari 0 malformation. Neurosurgery 48:1050-1054; discussion 10541055, 2001

33. Tubbs RS, McGirt MJ, Oakes WJ: Surgical experience in 130 pediatric patients with Chiari I malformations. J Neurosurg 99: 291-296, 2003

34. Vanaclocha V, Saiz-Sapena N: Duraplasty with freeze-dried cadaveric dura versus occipital pericranium for Chiari type I malformation: Comparative study. Acta Neurochir (Wien) 139: 112-119, 1997

35. Vargas MI, Delavelle J, Jlassi H, Rilliet B, Viallon M, Becker CD, Lövblad KO: Clinical applications of diffusion tensor tractography of the spinal cord. Neuroradiology 50:25-29, 2008

36. Vedantam A, Jirjis MB, Schmit BD, Budde MD, Ulmer JL, Wang MC, Kurpad SN: Diffusion tensor imaging and tractography in Brown-Sequard syndrome. Spinal Cord 50:928-930, 2012

37. Vega A, Quintana F, Berciano J: Basichondrocranium anomalies in adult Chiari type I malformation: A morphometric study. J Neurol Sci 99:137-145, 1990 